\title{
Infoxicação, políticas públicas e educação
}

\author{
Anelise Maya Kwiecinski \\ Instituto Federal do Rio Grande do Sul (IFRS) - Campus Porto Alegre \\ (anelise.maya@hotmail.com) \\ Silvia de Castro Bertagnolli \\ Instituto Federal do Rio Grande do Sul (IFRS) - Campus Porto Alegre \\ (silvia.bertagnolli@poa.ifrs.edu.br) \\ Márcia Amaral Corrêa Ughini Villarroel \\ Instituto Federal do Rio Grande do Sul (IFRS) - Campus Sertão \\ (marcia.correa@sertao.ifrs.edu.br)
}

\begin{abstract}
Resumo: O termo infoxicação foi criado por Alfons Cornella, na década de 90, para explicar a dificuldade em digerir o excesso de informação oferecida diariamente no meio digital e também distinguir a qualidade, veracidade e relevância das informações a serem absorvidas. A infoxicação se manifesta na busca, seleção e no processamento das informações e suas consequências são preocupantes: desde ansiedade e estresse até sintomas somáticos que prejudicam àreas importantes da vida, além da área educacional. Políticas públicas de segurança na internet têm se tornado indispensáveis para combater este fenômeno. Quanto ao contexto educacional, a escola é um lugar onde os alunos aprendem a ter visão crítica para poderem atribuir significados às mensagens, informações e conteúdos recebidos dos meios digitais. Esta é uma pesquisa bibliográfica exploratória que apresenta uma breve discussão sobre a infoxicação e como utilizar as políticas de segurança existentes para auxiliar os nativos digitais, que são os estudantes conectados aos dispositivos de acesso à internet desde o início da vida, principalmente no contexto escolar. Acredita-se que, quanto mais informação os pais, profissionais e alunos tiverem acerca do tema como um fenômeno contemporâneo e grave, mais possa trabalhar-se com foco em prevenção e intervenções mais assertivas.
\end{abstract}

Palavras-chave: Infoxicação; Políticas públicas; Contexto escolar.

\section{Infoxication, public policies and education}

Abstract: The term infoxicação was created by Alfons Cornella in the 90's to explain the difficulty in digesting the excess of information offered daily in the digital environment and also to distinguish the quality, truthfulness and relevance of the information to be absorbed. The information is expressed in the search, selection and processing of the information and its consequences are worrisome. Public security policies on the Internet have become indispensable to combat this phenomenon. As for the educational context, the school is a place where students learn to have critical reason to be able to attribute meanings to the messages, information and contents received from the digital media. This is an exploratory research that presents a brief discussion about infoxicación and how to use existing security policies to assist the digital natives, mainly in the school context. It is believed that the more information parents, professionals and students have about the subject as a contemporary and serious phenomenon, the more work can be done with a focus on prevention and more assertive interventions.

Keywords: Infoxication; Public policies; School context. 


\section{INTRODUÇÃO}

Desde o surgimento de tecnologias digitais da comunicação e informação como a internet, o computador, os celulares e smartphones, é possível observar uma mudança considerável nos costumes, hábitos, relações interpessoais e até mesmo na forma como os indivíduos se percebem no mundo. Estas mudanças são graduais e trazem consigo novas formas de interação e consumo na atualidade. Novos aparatos surgem diariamente, complementando a vida moderna. $E$ os nativos digitais, de Prensky (2001), convivem com estas tecnologias da informação e da comunicação (TICs) desde seu nascimento. São adultos, jovens e crianças que têm acesso rápido e facilitado ao universo das informações digitais.

Segundo o suplemento de Tecnologias da Informação e Comunicação da Pesquisa Nacional por Amostra de Domicílios realizada pelo IBGE (2016a), realizado em convênio com o Ministério das Comunicações, pela primeira vez, o acesso à Internet via telefone celular nos domicílios brasileiros ultrapassou o acesso via microcomputador: de 2013 para 2014, entre os domicílios que acessaram a Internet (inclusive os que utilizaram mais de uma forma de acesso), o percentual dos que o fizeram por microcomputador recuou de $88,4 \%$ para $76,6 \%$, enquanto a proporção dos domicílios que acessavam a Internet por celular saltou de 53,6\% para $80,4 \%$. Ou seja, em todos os contextos existentes - organizacional, hospitalar, militar, acadêmico ou mesmo em casa - são utilizadas ferramentas de fácil acesso às tecnologias digitais informacionais para tomada de decisões, solução de problemas, negociações, aprendizagem e interação.

Mas, se por um lado é fantástico o acesso a tantos conteúdos em apenas um clique, por outro, o bombardeamento por uma quantidade excessiva de informações pode deixar as pessoas menos informadas, por mais paradoxal que pareça. Com a rapidez dos processos digitais, o excesso de informações e a escassez de espaços/tempo para abstração e reflexão, acaba-se por intensificar a produção de uma enorme quantidade de lixo digital e dados falsos, apontam Coll \& Monereo et al. (2011).

Nesse sentido é que se apresenta a temática da infoxicação. Esse termo foi criado por Alfons Cornella, na década de 90, para explicar a dificuldade em digerir o excesso de informação oferecida diariamente no meio digital e também distinguir a qualidade, veracidade e relevância das informações a serem absorvidas. Este 
processo faz com que se compartilhem informações falsas, assim, multiplicando a infoxicação no meio digital a cada dia.

Algumas pesquisas sobre o impacto das tecnologias informacionais no aprendizado e na retenção de informação dos nativos digitais apresentadas no Livro de Atas do Primer Congreso Internacional Infoxicación: Mercado de la Información y Psique (MANCINAS-CHÁVEZ et al., 2014), em Sevilla/Espanha, indicam que apesar de mais expostos à diversidade de informações virtuais, estes absorvem um conteúdo mais superficial e dissociado, consequência da falta de habilidades e orientação para utilização e entendimento do que pesquisam e encontram.

Outras consequências do uso inadequado e desenfreado das tecnologias de comunicação e informação digitais são a nomofobia e a ansiedade informacional, que representam, para Maziero e Oliveira (2016), a necessidade constante de estar utilizando o computador ou estar com o celular em mãos, recebendo informações, comunicando-se, tornando-se estas tecnologias um amuleto na vida dos nativos digitais.

Portanto, a escolha do tema deste artigo pautou-se no cenário atual de perigos e consequências que o uso equivocado das tecnologias da informação e comunicação pode causar aos nativos digitais, sendo que estes não possuem orientação suficiente ou o auxílio necessário para lidarem com a internet (COLL; MONEREO et al., 2011). A infoxicação acaba por atingir a escola, espaço onde os nativos digitais passam parte do seu dia para aprender, conviver e transformar as informações que recebem em aprendizagens significativas.

Assim, buscou-se nesse estudo exploratório abordar o fenômeno infoxicação e suas consequências; elencar os programas, ações e decisões tomadas pelos governos e/ou entes públicos e privados para assegurar a segurança na internet; além de falar sobre o contexto escolar e sua necessidade de atualização e atenção relacionadas à internet.

Este artigo encontra-se organizado da seguinte forma: a seção 2 apresenta a temática da internet e as fontes de informação mais utilizadas pelos nativos digitais atualmente; descreve o que é a infoxicação e como ela afeta a vida pessoal e acadêmica destes jovens; elenca algumas das políticas existentes sobre a segurança na internet; aponta o contexto escolar e a necessidade de formação dos professores para a capacitação dos alunos no uso da internet. A metodologia é 
abordada na seção 3. Uma breve discussão é apresentada na seção 4 e as conclusões são apresentadas na seção 5.

\section{MÉTODO}

Esta é uma pesquisa exploratória, que busca proporcionar uma visão geral acerca do tema abordado. Para Gil (2008), este tipo de pesquisa é realizado, sobretudo, quando o tema é pouco explorado e torna-se difícil formular hipóteses precisas, o que é verídico neste caso. Como o nome sugere, a pesquisa exploratória procura explorar um problema ou uma situação para prover critérios e compreensão.

Como há poucos estudos envolvendo as áreas abordadas, esta pesquisa tem por objetivo conhecer com maior profundidade a infoxicação e suas consequências, as políticas públicas de combate ao fenômeno e as intervenções possíveis no contexto escolar, reunindo estas informações através de uma pesquisa bibliográfica, a partir de livros, artigos, cartilhas e sites oficiais que abrangem os assuntos acima citados.

\section{FUNDAMENTAÇÃO TEÓRICA}

\section{A INTERNET E AS FONTES INFORMACIONAIS}

Vivenciamos uma sociedade imersa à cultura digital ou cibercultura. Os nascidos a partir da década de 80 experimentam novas possibilidades comunicacionais e informacionais quase que instantaneamente, através do universo digital (PALFREY; GASSER, 2011).

Muitas são as terminologias utilizadas para designar esses que sempre conviveram conectados às tecnologias digitais: Geração Digital, Geração Net, Geração Y, Millennials ou Nativos Digitais (PALFREY; GASSER, 2011; MARTINS, 2015). Entretanto, Martins (2015) explica que mais importante que a nomenclatura é a forma desta geração se relacionar com o mundo. Há uma nova organização econômica, social, política e cultural, identificada como Sociedade da Informação (SI), que com todas suas peculiaridades, apresenta características que impõem novos desafios em relação ao papel da educação em uma sociedade tecnológica. 
A SI, mediada pelas tecnologias de informação e comunicação digitais (TICs), tem provocado mudanças nas formas do homem produzir e acessar informação e conhecimento (LINHARES; CERVERÓ; PAIXÃO, 2017). Segundo as pesquisas mais recentes do IBGE, de 2013 para 2014, a proporção de pessoas com 10 anos ou mais de idade que acessaram a Internet por equipamentos eletrônicos diferentes do microcomputador saltou de $4,2 \%$ para $10,5 \%$. Em números absolutos, esse crescimento foi de 155,6\% (ou mais 11,2 milhões de pessoas) (IBGE, 2016b).

Dessa forma, de acordo com Lorenzo (2013), as pessoas que acessavam a internet apenas com computadores (desktop) agora desfrutam dos benefícios da mobilidade com notebooks, celulares, smartphones, que nos permitem estar sempre conectados à rede de qualquer local.

$E$ as redes sociais tornaram-se um meio muito utilizado como meio informacional da população em geral (LORENZO, 2013), já que enquanto navegam, recebem muitas notícias, até mesmo de forma personalizada, de acordo com a descrição de seu perfil e interesses. Twitter e Facebook, sites de vídeos, como YouTube, e programas de chat, como Messenger e Skype, além de milhares de blogs e sites, elevam a web a um patamar ímpar na circulação de informação.

Portanto, a informação é a matéria-prima da SI. Logo, as TICs, e especialmente as tecnologias de redes de informação, oportunizaram um grande aumento da quantidade e do fluxo de informação, causando um verdadeiro bombardeio informativo (COLL; MONEREO et al., 2011).

Neste sentido, uma reflexão importante apontada por Passadori (2014) - sob um ponto de vista organizacional, mas generalizável - é que mesmo a capacidade de assimilação sendo diferente entre as pessoas, se torna notável ue para todas há um excesso. Uma sobrecarga de informações e dados que não podem ser incorporados e que, desta forma, não serão transformados em conhecimento.

Infoxicação

A partir da breve introdução anterior, é possível adentrar no conceito de infoxicação. Esse neologismo foi criado pelo físico Alfons Cornella (1996) unindo as palavras informação e intoxicação (intoxicação informacional).

O significado do termo se relaciona à dificuldade em digerir o excesso de informação oferecida no meio digital e em distinguir a qualidade, veracidade e 
relevância desta informação a ser absorvida (PEDRO, 2016). Os nativos digitais muitas vezes infoxicados - não possuem habilidades suficientes para utilização assertiva das informações virtuais (LINHARES; CERVERÓ; PAIXÃO, 2017).

O ciclo da infoxicação se apresenta, segundo Rodrigues \& Barrio (2015), com a urgência de produção de informações nos meios digitais, seguido de um produto pouco elaborado e de baixa qualidade, o que leva a um conteúdo com pouca contribuição substancial adicionado a uma quantidade de informações que já circulam na rede. Tudo isso somado ao despreparo do usuário, que não sabe em qual informação confiar, e acaba por selecionar mais informações porque precisa contrastar mais estas notícias.

$\mathrm{E}$, de acordo com os mesmos autores supracitados, ela se manifesta em três fases: na busca, através da sobrecarga informacional; na seleção, pela falta de filtros para comprovação da veracidade das informações; e do processamento, já que todo este processo fragmenta a leitura e baixa a concentração/atenção, fazendo com que as informações falsas (fake news) sejam compartilhadas e aceitas sem questionamento pelos nativos digitais.

Já com relação às consequências deste processo, Passadori (2014) alerta para os possíveis sintomas advindos deste fenômeno: desde desordens do humor, aumento da irritabilidade e dificuldade para dormir até queda de produtividade escolar/laboral, dificuldades de aprendizagem e retenção de informações, aumentando os níveis do estresse.

O abuso destas ferramentas informacionais pode causar ansiedade, sensação de desinformação e desatualização em curto período de tempo, nervosismo, dependência e predisposição aos transtornos de ansiedade. Esse medo patológico de permanecer sem contato com as tecnologias, chamado nomofobia, elucida o grande descontrole e desorientação dos jovens frente à utilização das ferramentas digitais de informação no cotidiano (MAZIERO; OLIVEIRA, 2016).

Mesmo que esses sintomas não surjam primariamente através da infoxicação, a sobrecarga de informação pode ser um contribuinte significativo.

\section{POLÍTICAS PÚBLICAS DE SEGURANÇA}

Pedro (2016) destaca a importância da reflexão sobre a qualidade das informações acessadas, visto que, embora a internet ofereça muitas informações, 
nem todas são confiáveis. Ou seja, ter acesso a uma abundância de informações não é sinônimo de estar bem informado. Afinal, não é nada fácil distinguir o que de fato é relevante, selecionar e analisar tanto conteúdo (KENSKI, 2015). Nestas circunstâncias, é claro o binómio: para mais informação é necessária mais formação.

Neste contexto, existe o CERT.br, que é o Grupo de Resposta a Incidentes de Segurança para a Internet brasileira, mantido pelo Núcleo de Informação e Coordenação do Ponto BR (NIC.br) do Comitê Gestor da Internet no Brasil, e responsável por tratar incidentes de segurança em computadores que envolvam redes conectadas à Internet brasileira (CERT.BR, 2019; NIC.BR, 2019).

As atividades conduzidas pelo CERT.br fazem parte das atribuições do Comitê Gestor da Internet no Brasil, de: a) estabelecer diretrizes estratégicas relacionadas ao uso e desenvolvimento da Internet no Brasil; b) promover estudos e recomendar procedimentos, normas e padrões técnicos e operacionais, para a segurança das redes e serviços de Internet, bem assim para a sua crescente e adequada utilização pela sociedade (CERT.BR, 2019).

Bem como dos objetivos do NIC.br, conforme seu Estatuto: a) atender aos requisitos de segurança e emergências na Internet Brasileira em articulação e cooperação com as entidades e os órgãos responsáveis; b) promover ou colaborar na realização de cursos, simpósios, seminários, conferências, feiras e congressos, visando contribuir para o desenvolvimento e aperfeiçoamento do ensino e dos conhecimentos nas áreas de suas especialidades (NIC.BR, 2019).

Assim, foi criada a Cartilha de Segurança para Internet (CERT.BR, 2012), com vistas a capacitar os nativos digitais, pais e professores quanto à navegação segura na internet, evitando as falsas notícias e atentando para o uso excessivo da internet, entre outras questões importantes na utilização da rede. Existem modelos adaptados para crianças e para adolescentes, a fim de que a linguagem e conteúdos estejam de acordo com cada perfil e necessidade do usuário. O site <internetsegura.br>, vinculado ao NIC.br (2019), disponibiliza todos estes conteúdos de segurança na internet.

Coll \& Monereo et al. (2011) certificam que a sobrecarga informacional e a circulação de informações incorretas, tendenciosas ou mal-intencionadas são fenômenos inevitáveis na Sociedade da Informação, sendo assim a implementação de programas formativos que facilitem, por parte dos usuários, a aquisição e o 
desenvolvimento das competências necessárias para enfrentá-los é a única linha de ação razoável.

\section{CONTEXTO ESCOLAR}

A compreensão sobre o fenômeno infoxicação implica na necessidade de novas formas de ensino-aprendizagem, reforça Kenski (2015), já que o contexto no qual os alunos estão inseridos exige destreza e competências digitais mais complexas, necessárias à interação aluno-conhecimento.

Segundo Coll \& Monereo et al. (2011), mesmo que os nativos digitais possuam maior fluência nas tecnologias que muitos professores, estes últimos são necessários e essenciais na mediação entre a busca e utilização de dados superficiais (adquiridos virtualmente sem crítica e reflexão) e conhecimentos relevantes ao aluno.

O que significa essa ideia? Que a escola é o lugar onde os alunos aprendem a ter pensamento crítico, a fim de poderem atribuir significados às mensagens, informações e conteúdos recebidos das mídias, multimídias e outras formas digitais de compartilhamento de informações (LIBÂNEO, 2011). No meio das informações em mosaico, fragmentadas entre a mentira e a verdade, cabe também a escola auxiliar os alunos na reestruturação, reordenação e criação de filtros para absorção de informações que tenham qualidade e procedência garantidas, promovendo meios de conhecimento real ao aluno.

Dessa forma, para os professores contribuírem no desenvolvimento de habilidades digitais e da criticidade dos alunos, eles também precisam ter uma formação e capacitações continuadas nas quais estas tecnologias sejam aplicadas e discutidas constantemente (LINHARES; CERVERÓ; PAIXÃO, 2017). Refletir sobre estas questões, diante do cenário atual, torna-se indispensável.

\section{DISCUSSÃO}

A partir dos dados apresentados, é possível iniciar uma breve discussão sobre a infoxicação e como utilizar as políticas de segurança existentes para auxiliar os nativos digitais, principalmente no contexto escolar, local propício para se 
capacitar e informar os jovens quanto aos perigos e prejuízos que o uso inadequado das informações no meio digital pode causar.

A internet é um potente meio de comunicação e informação, de fato. Seria muito difícil, para algumas pessoas, imaginar como seria a vida sem poder usufruir das diversas facilidades e oportunidades trazidas por esta tecnologia, aponta Lorenzo (2013). Porém, quanto maior o contato, maior a necessidade de reflexão acerca da forma em que está sendo usada.

Com relação à hiperconectividade, os jovens utilizam as redes sociais praticamente o tempo todo, comunicando-se e fornecendo informações pessoais. Esta forma de uso excessivo das ferramentas de comunicação e informação tornase prejudicial no momento em que as notificações e mensagens instantâneas atrapalham a aprendizagem e também a relação interpessoal destas pessoas, segundo Rodrigues \& Barrio (2015).

A infoxicação é um grande alerta à forma de consumo de informações atual. Estima-se que, em apenas um minuto, são compartilhados, em média, 2.460.000 conteúdos no Facebook; 277,00 novos tweets publicados; 216,000 fotos carregadas para o Instagram; e adicionadas 72 horas de vídeo no YouTube (DOMO, 2019). E estes os números dizem respeito apenas à atividade nas redes sociais, mas o volume ainda está crescendo mais fora deles, de acordo com Rodrigues \& Barrio (2015). Portanto, o excesso de trabalho mental que envolve a assimilação de mais dados do que a capacidade do ser humano permite leva o indivíduo à infoxicar-se (CORNELLA, 1996).

As consequências deste processo são preocupantes. Pensando na nomofobia, viver com um medo intenso de ficar longe de dispositivos conectados à internet pode causar prejuízos na vida laboral, pessoal e acadêmica do indivíduo, conforme Maziero \& Oliveira (2017). Outra consequência importante é a sensação de desconfiança e insegurança, que advém da falta de veracidade das muitas informações disponíveis no meio digital.

E a saturação de informações pode ocorrer durante o processo de seleção e filtragem, por causa da falta de habilidades pessoais e estratégias dos indivíduos ao gerenciar as informações disponíveis. Assim, instrumentos como as cartilhas de segurança na internet e os guias de internet segura (CERT.BR, 2012), para crianças, pais e professores, tornam-se indispensáveis para orientação no uso assertivo da internet e suas ferramentas de acesso. 
Estes instrumentos criados pelo CERT.br auxiliam a estabelecer diretrizes estratégicas relacionadas ao uso e desenvolvimento da Internet no Brasil e a promover estudos e recomendar procedimentos, normas e padrões técnicos e operacionais, para a segurança das redes e serviços de Internet, bem assim para a sua crescente e adequada utilização pela sociedade.

A quantidade de informações recebidas deve ser dosada e, para isso, necessita-se de um preparo e adaptação dos nativos digitais à sobrecarga de informações a qual são expostos todos os dias. No contexto escolar, a equipe diretiva e os professores podem e devem fazer uso destes instrumentos de orientação para auxiliar os jovens na fuga contra a infoxicação.

A escola é um espaço provedor de informação, em meio à sociedade digital na qual estamos inseridos. Cabe a ela auxiliar na atribuição de significados às informações, já que as tecnologias informáticas não substituem a relação docentealuno, a qual possibilita o desenvolvimento de capacidades intelectuais e afetivas ao aluno, tornando-o mais reflexivo quanto ao que recebe e o que irá utilizar a partir disso (LIBÂNEO, 2011).

Nesse sentido, capacitações contínuas de professores na área de informática na educação podem ser meios poderosos de unir o contexto escolar à realidade virtual dos alunos, instrumentalizando-os no combate à infoxicação por meio do ensino de seleção e filtragem de informações e do auxílio na transformação destas informações em conhecimento e aprendizagens significativas à vida do aluno. "O aprendizado se substancia especialmente fora do espaço formal, daí a importância de incluir dentro do próprio ambiente acadêmico virtual espaços e informações que completem o processo de formação dos estudantes" (LORENZO, 2013, p.34).

Portanto, o objetivo desta pesquisa foi refletir sobre o panorama atual da sociedade da informação na internet, do ponto de vista atual, bem como os novos desafios relacionados aos riscos inerentes ao fato de que a humanidade, como um todo, nunca teve antes de ter tido um acesso tão rápido a um volume de dados que aumenta a cada segundo.

\section{CONCLUSÕES}

A informática já faz parte da história humana, e sem essa tecnologia é impossível imaginar como seria feita a troca de informações e atualizações de dados 
em tempo real, da forma em que ocorre nos dias atuais (LORENZO, 2013). A partir disso, criar políticas voltadas ao seu uso - segurança, privacidade e limitações -, torna-se indispensável na sociedade hiperconectada em qual vivemos.

Este foi um estudo exploratório. Certamente, situações com mais vivências para análise produzam resultados mais precisos e esclarecedores. A temática infoxicação possui poucos estudos publicados no Brasil, apesar da amplitude mundial deste fenômeno, que causa grandes consequências na vida dos cidadãos infoxicados.

Faz-se necessário o alerta sobre este fenômeno chamado infoxicação. É um problema que relaciona a sobrecarga de informações, juntamente à falta de veracidade e desconfiança acerca das informações e conteúdos que circulam na internet. Ações para minimizar seus efeitos e consequências na área psicológica e também na aprendizagem são urgentes e necessárias.

Acredita-se que, quanto mais informação pais, profissionais e alunos tiverem acerca do tema como um fenômeno contemporâneo e grave, mais possa trabalharse com foco em prevenção e intervenções mais assertivas, assim como a ênfase na temática de segurança na internet, tanto no contexto escolar, quanto na sociedade em geral.

\section{REFERÊNCIAS}

CERT.BR (Brasil). Cartilha de Segurança para Internet. Versão 4.0 / CERT.br. [São Paulo, SP]: Comitê Gestor da Internet no Brasil, 2012. Disponível em:

https://cartilha.cert.br/livro/cartilha-seguranca-internet.pdf. Acesso em: 28 nov. 2017.

CERT.BR (Brasil). Sobre o CERT.br. [São Paulo, SP]: Comitê Gestor da Internet no Brasil, 2019. Disponível em: https://cert.br/sobre/. Acesso em: 28 nov. 2017.

COLL, C; MONEREO, C. et al. Psicologia da Educação Virtual: Aprender e Ensinas com as Tecnologias da Informação e da Comunicação. Porto Alegre: ArtMed, 2011.

CORNELLA, A. Cómo darse de baja y evitar la infoxicación en Internet. Extra!-Net. Revista de Infonomía, 1996.

DOMO. Data Never Sleeps 7.0. Domo Inc., 2019. Disponível em: https://www.domo.com/learn/data-never-sleeps-7. Acesso em: 23 mai. 2018. 
GIL, A. C. Como elaborar projetos de pesquisa. 4. ed. São Paulo: Atlas, 2008.

IBGE (Brasil). Pesquisa nacional por amostra de domicílios: síntese de indicadores, 2015. [Rio de Janeiro]: Coordenação de Trabalho e Rendimento, 2016a. Disponível em: https://biblioteca.ibge.gov.br/index.php/bibliotecacatalogo?view=detalhes\&id=298887. Acesso em: 28 nov. 2017.

IBGE (Brasil). Acesso à internet e à televisão e posse de telefone móvel celular para uso pessoal: 2015. [Rio de Janeiro]: Coordenação de Trabalho e Rendimento, 2016b. Disponível em: https://biblioteca.ibge.gov.br/visualizacao/livros/liv99054.pdf. Acesso em: 28 nov. 2017.

KENSKI, V. M. Educação e Tecnologias: o novo ritmo da informação. Campinas: Papirus, 2015.

LIBÂNEO, J. C. Adeus professor, adeus professora? Novas exigências educacionais e profissão docente. 13. ed. Editora: Cortez, 2011.

LINHARES, R. N.; CERVERÓ, A. C.; PAIXÃO, P. B. S. Pesquisa Online como Estratégia Pedagógica nos Contextos Científicos da Cibercultura. Centro de Estudos Medievais - Oriente \& Ocidente - Feusp, Universidade de São Paulo, SP, 2017. Disponível em: http://www.hottopos.com/notand43/9rn.pdf. Acesso em: 26 jun. 2017.

LORENZO, E. W. C. M. A utilização das Redes Sociais na Educação. 3. ed. Rio de Janeiro: Editora Clube de Autores, 2013.

MANCINAS-CHÁVEZ, R. et al. Primer Congreso Internacional Infoxicación: mercado de la información y psique, Libro de Actas. Sevilla: Ladecom, Facultad de

Comunicación, Universidad de Sevilla, 2014. Disponível em:

https://idus.us.es/xmlui/handle/11441/30860. Acesso em: 25 jun. 2017.

MARTINS, C. Geração digital, geração net, millennials, geração Y: refletindo sobre a relação entre as juventudes e as tecnologias digitais. Diálogo, Canoas, n. 29, p.141151, ago. 2015. Disponível em:

http://revistas.unilasalle.edu.br/index.php/Dialogo/article/view/2238-9024.15.7/pdf.

Acesso em: 25 jun. 2017.

MAZIERO, M. B.; OLIVEIRA, L. A. Nomofobia: uma revisão bibliográfica. Unoesc \& Ciência. Santa Catarina, v. 8, n. 1, p. 73-80, jun. 2017. Disponível em: http://editora.unoesc.edu.br/index.php/acbs/article/view/11980. Acesso em: 26 nov. 2017.

NIC.BR (Brasil). Sobre o NIC.br. [São Paulo, SP]: O Núcleo de Informação e Coordenação do Ponto BR - NIC.br, 2019. Disponível em: https://www.nic.br/quemsomos/. Acesso em: 28 nov. 2017.

PALFREY, J.; GASSER, U. Nascidos na Era Digital: entendendo a primeira geração de nativos digitais. Porto Alegre: Artmed, 2011. 
PASSADORI, R. Quem Não Comunica Não Lidera [recurso eletrônico]. 2. ed. Atlas, 2014.

PEDRO, K. M. Competências Digitais e Segurança na Internet: informativo e orientações para pais, professores e estudantes. [Marília]: UNESP, 2016.

Disponível em: https://repositorio.unesp.br/handle/11449/148563. Acesso em: 25 jun. 2017.

PRENSKY, M. Nativos digitais, Imigrantes digitais [recurso eletrônico]. 2001. Disponível em:

http://www.colegiongeracao.com.br/novageracao/2_intencoes/nativos.pdf. Acesso em: 16 nov. 2017.

RODRÍGUEZ, R. F.; BARRIO, M. G. Infoxicación: implicaciones del fenómeno en la profesión periodística. Revista de Comunicación de la SEECI, p. 141-181, nov. 2015. Disponível em: http://www.seeci.net/revista/index.php/seeci/article/view/340. Acesso em: 26 nov. 2017. 